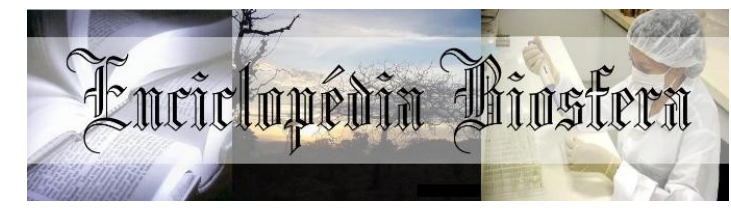

\title{
INTERPRETAÇÕES ECOLÓGICAS DA ANATOMIA FOLIAR DE Acacia mangium WILLD (FABACEAE- MIMOSOIDEAE)
}

\author{
Francisco Jairo Lima da Silva ${ }^{1}$, Deolinda Lucianne Ferreira Garcia²
}

1Bacharel em Engenharia Florestal da Universidade do Estado do Amazonas (UEA), Itacoatiara-AM, Brasil.

2 Professora Doutora do curso de Engenharia Florestal da UEA, Itacoatiara-AM, Brasil. E-mail: dlferreira@uea.edu.br

Recebido em: 15/02/2020 - Aprovado em: 15/03/2020 - Publicado em: 30/03/2020

DOI: 10.18677/EnciBio_2020A10

\begin{abstract}
RESUMO
Análises da anatomia foliar contribuem para o entendimento dos processos ecológicos das espécies. O objetivo deste estudo foi caracterizar a anatomia foliar de Acacia mangium Willd e avaliar sua densidade estomática em plantios de diferentes idades, contribuindo para o conhecimento anatômico e entendimento dos processos ecológicos da espécie. Para isso, foram coletadas folhas de indivíduo de nove meses, um ano e nove meses e de três anos e sete meses e realizadas técnicas usuais para estudo de anatomia foliar. Acacia mangium Willd possui folhas anfiestomáticas com estômatos do tipo paracíticos e anisocíticos. Em vista frontal, as células epidérmicas possuem formato e tamanho irregular com paredes lisas. Em secção transversal, a epiderme é unisseriada, o mesofilo é do tipo isolateral e a nervura central apresenta formato biconvexo, sendo composta por dois feixes vasculares, do tipo colateral, na forma de arco. A densidade estomática média nos indivíduos de diferentes idades variou entre 29,74 e 33,08 estômatos $/ \mathrm{mm}^{2}$, porém há evidência moderada $(p=0,06)$ para afirmar que a densidade estomática difere conforme a idade dos indivíduos. Em geral, as características anatômicas de Acacia mangium Willd justificam o seu rápido crescimento e adaptação em ambiente exposto a alta intensidade luminosa.
\end{abstract}

PALAVRAS-CHAVE: densidade estomática, ecofisiologia, folhas anfiestomáticas.

\section{ECOLOGICAL INTERPRETATION OF THE LEAF ANATOMY OF Acacia mangium WILLD (FABACEAE- MIMOSOIDEAE)}

\begin{abstract}
Leaf anatomy analyzes contribute to the understanding of the ecological processes of the species. The objective of this study was to characterize the Acacia mangium Willd leaf anatomy and evaluate its stomatal density in different age plantings, contributing to the anatomical knowledge and understanding of the ecological processes of the species. For this, leaves were collected from individuals of nine months, one year and nine months and three years and seven months and usual techniques were used to study leaf anatomy. Acacia mangium Willd has amphistomatous leaves with paracytic and anisocytic stomata. In front view, epidermal cells have irregular shape and size with smooth walls. In cross section, the epidermis is uniseriate, the mesophyll is of the isolation type and the central vein has
\end{abstract}


a biconvex shape, being composed of two colateral vascular bundles, in the form of an arc. The average stomatal density in individuals of different ages ranged from 29,74 to 33,08 stomata $/ \mathrm{mm}^{2}$, but there is moderate evidence $(p=0,06)$ to state that stomatal density differs according to the age of the individuals. In general, the anatomical characteristics of Acacia mangium Willd justify its rapid growth and adaptation in an environment exposed to high light intensity.

KEYWORDS: stomatal density, ecophysiology, amphistomatous leaves.

\section{INTRODUÇÃO}

Acacia mangium Willd (Fabaceae-Mimosoideae), natural da região noroeste da Austrália, Papua Nova Guiné e leste da Idonésia, é uma espécie heliófita de rápido crescimento e ampla variedade de adaptabilidade (JUSOH et al. 2017). Apresenta alta tolerância a condições de estresse hídrico e deficiência nutricional no solo (REYES et al., 2018), sendo considerada promissora para o reflorestamento nos trópicos, com grande potencial para plantio florestal com objetivo de produzir madeira serrada, celulose e geração de energia (TONINI et al. 2018). O plantio comercial da espécie desempenha papel importante na manutenção do suprimento comercial de toras, reduzindo assim a demanda de madeira da floresta natural (JUSOH et al. 2017). Em Itacoatiara-AM o grupo empresarial André Maggi possui plantios de diferentes idades de Acacia mangium Willd, plantada em área aberta (sem sombreamento), voltadas para retirada de biomassa e posterior produção de energia. Em um dos plantios da empresa André Maggi, a Acacia mangium Willd atingiu o incremento médio anual em altura e volume de respectivamente, $3,30 \mathrm{~m} e$ $51,87 \mathrm{~m}^{3}$ há $^{-1}$ ano $^{-1}$ (MACHADO et al. 2018).

As investigações sobre as características ecológicas das espécies permitem compreender o padrão de crescimento e adaptabilidade às condições do ambiente (SOUZA et al., 2017). Auxiliando o manejo adequado das espécies (Schöngart et al., 2015), bem como a seleção de espécie com potencial para atender o objetivo do plantio (FERREIRA; TONINI, 2009).

A anatomia foliar constitui ferramenta para melhor entendimento das adaptações das plantas às condições ambientais, possibilitando interpretar suas estruturas e funções ecológicas (LEME; DIAS, 2014; ZHOU et al., 2019), contribuindo ainda para a identificação das espécies, principalmente espécies morfologicamente semelhantes (LEME; DIAS, 2014; SILVA et al., 2018; VAZ et al., 2019). As análises da estrutura interna das folhas podem subsidiar informações que permitem identificar características estruturais que favorecem o estabelecimento de espécies em determinados ambientes (FERREIRA et al. 2015), e ainda subsidiar informações relevantes para a fisiologia e ecologia das espécies (RODRIGUES et al. 2015).

O objetivo deste estudo foi caracterizar a anatomia foliar de Acacia mangium Willd e avaliar sua densidade estomática em plantios de diferentes idades, contribuindo para o conhecimento anatômico e entendimento dos processos ecológicos da espécie. Foram abordadas mais especificamente as seguintes questões: (i) quais características estruturais da anatomia foliar possibilita o estabelecimento e rápido crescimento de Acacia mangium Willd em plantio florestal aberto (sem sombreamento)? (ii) a densidade estomática difere entre indivíduos de diferentes idades? As hipóteses levantadas foram: (i) a espécie possui características estruturais da anatomia foliar que lhe permite o estabelecimento e boa performance do crescimento em plantios florestais abertos e (ii) a densidade 
estomática pode aumentar proporcionalmente ao aumento da idade dos indivíduos para a espécie atingir maior taxa de crescimento.

\section{Coleta do material botânico}

\section{MATERIAL E MÉTODOS}

As amostras foram coletadas no plantio de Acacia mangium Willd pertencente ao Grupo empresarial André Maggi, no imóvel denominado de Bom Sucesso, localizado no Km 33 da rodovia estadual AM-010, município de Itacoatiara - AM (figura 1). Foram coletadas folhas de indivíduos de nove meses, um ano e nove meses e de três anos e sete meses, em diferentes posições da árvore, ápice, meio e base, retirando-se somente folhas adultas e em boas condições fitossanitárias. O material vegetal foi transportado para o laboratório de Biologia da Universidade do Estado do Amazonas - UEA e estocados em frasco de vidro com álcool $70 \%$ para posterior utilização.
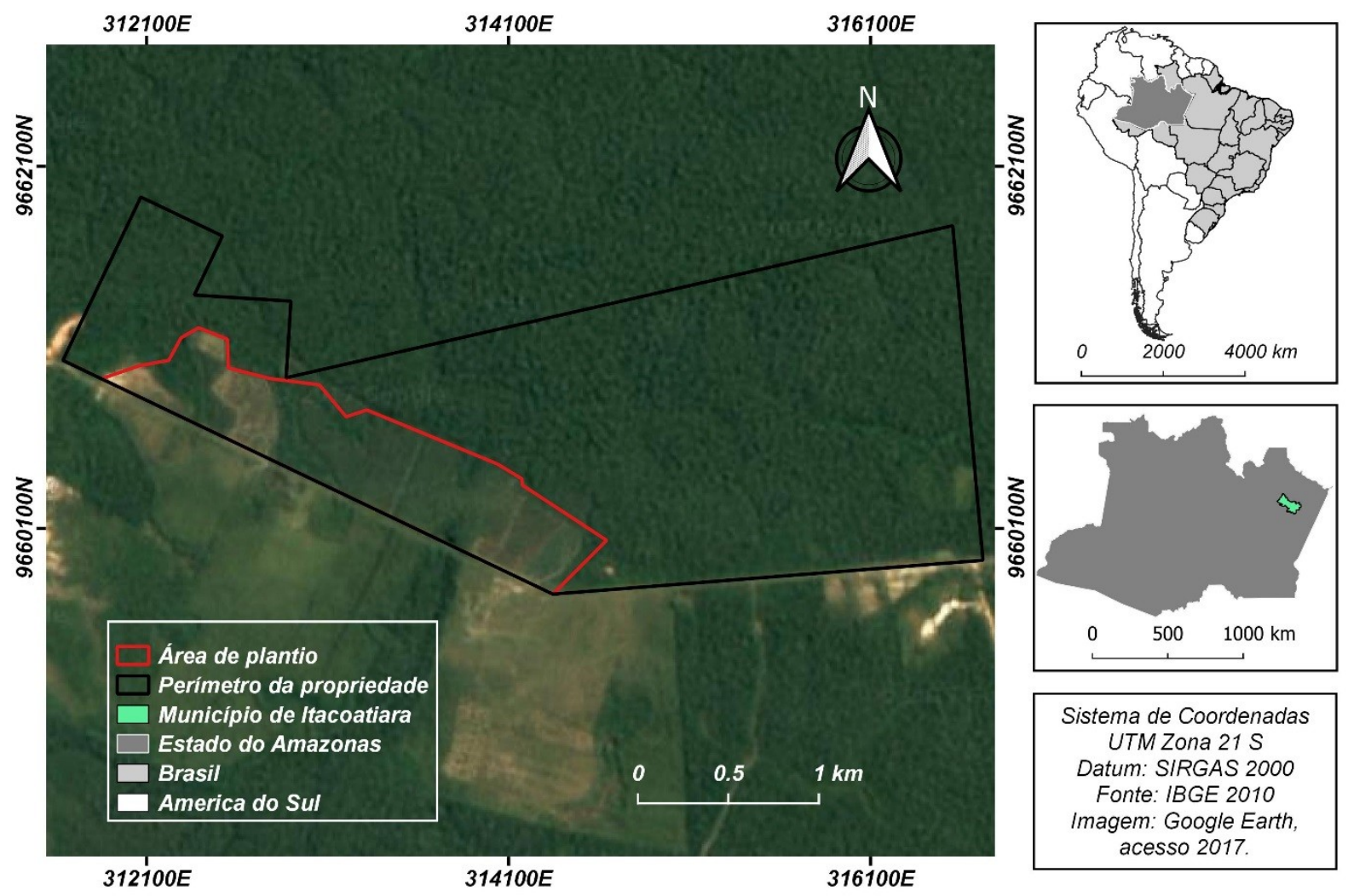

Sistema de Coordenadas UTM Zona $21 \mathrm{~S}$

Datum: SIRGAS 2000 Fonte: IBGE 2010 Imagem: Google Earth, acesso 2017.

FIGURA 1 - Localização da área de coleta do material botânico.

Preparo das lâminas histológicas

As etapas de preparo das lâminas foram realizadas no laboratório de Biologia da Universidade do Estado do Amazonas - UEA em Itacoatiara e no laboratório de Botânica Agroflorestal da Universidade Federal do Amazonas LABAF/UFAM em Manaus. No laboratório de Biologia da UEA foram confeccionadas as lâminas para descrição da epiderme e análise da densidade estomática dos indivíduos de diferentes idades. Para isso, cortes de aproximadamente um centímetro quadrado foram retirados da base, borda da região mediana da nervura e do ápice das folhas. As epidermes foram dissociadas através de imersão em 
hipoclorito de sódio durante cinco dias, período necessário para a dissociação. Em seguida os cortes foram varridos para retirada do mesofilo e o material obtido foi corado com safrablau e as lâminas montadas em glicerina. No LABAF/UFAM foram confeccionadas lâminas histológicas para análise da secção transversal das folhas dos indivíduos de 9 meses de idade. Para isso, cortes anatômicos transversais foram feitos na porção mediana do limbo à mão livre com auxílio de lâmina de barbear em micrótomo manual. Os cortes foram imersos em água sanitária até sua completa clarificação e depois lavados por duas vezes em água destilada e uma vez em água acética e posteriormente coradas com Azul de Astra e Safranina e montadas com gelatina glicerinada.

\section{Caracterização da anatomia foliar}

Para caracterizar a anatomia foliar de Acacia mangium Willd foram utilizadas as lâminas histológicas referente aos indivíduos de nove meses de idade. As lâminas foram analisadas com auxílio de microscópio óptico e registradas com obtenção de imagens obtidas de microscópio óptico Axioskop com câmera MC 80 no LABAF/UFAM. Os estômatos foram classificados levando em consideração a posição das células adjacentes ao estômato com relação as células-guarda, conforme proposto por Cutter (2002). As demais estruturas anatômicas foram caracterizadas de acordo com o guia ilustrativo de anatomia vegetal de Bona et al. (2004) e literatura especializada (CUTTER, 2002; CUTLER et al., 2011).

\section{Análise da densidade estomática}

A densidade estomática, número de estômatos por unidade de área, foi calculada para cada tratamento (plantios de diferentes idades), sendo determinada pela contagem de estômatos de 30 campos microscópicos observados na objetiva de 40x e ocular de 10x, o que proporcionou um aumento de 400x. O número de estômatos observados em cada campo foi dividido por $0,39 \mathrm{~mm}^{2}$ (área do campo), obtendo a densidade estomática em $\mathrm{mm}^{2}$. Em seguida, foi calculada a média dos 30 campos para obter a densidade estomática média para cada tratamento. Os dados de densidade estomática média para cada tratamento foram submetidos à análise de variância e suas médias comparadas pelo teste de Tukey ao nível de $5 \%$ de probabilidade.

\section{RESULTADOS E DISCUSSÃO}

Anatomia foliar de Acacia mangium Willd

A espécie Acacia mangium Willd possui folhas anfiestomáticas e estômatos do tipo paracíticos e anisocíticos, com células epidérmicas, em vista frontal, de formato e tamanho irregular com paredes lisas (figura 2).

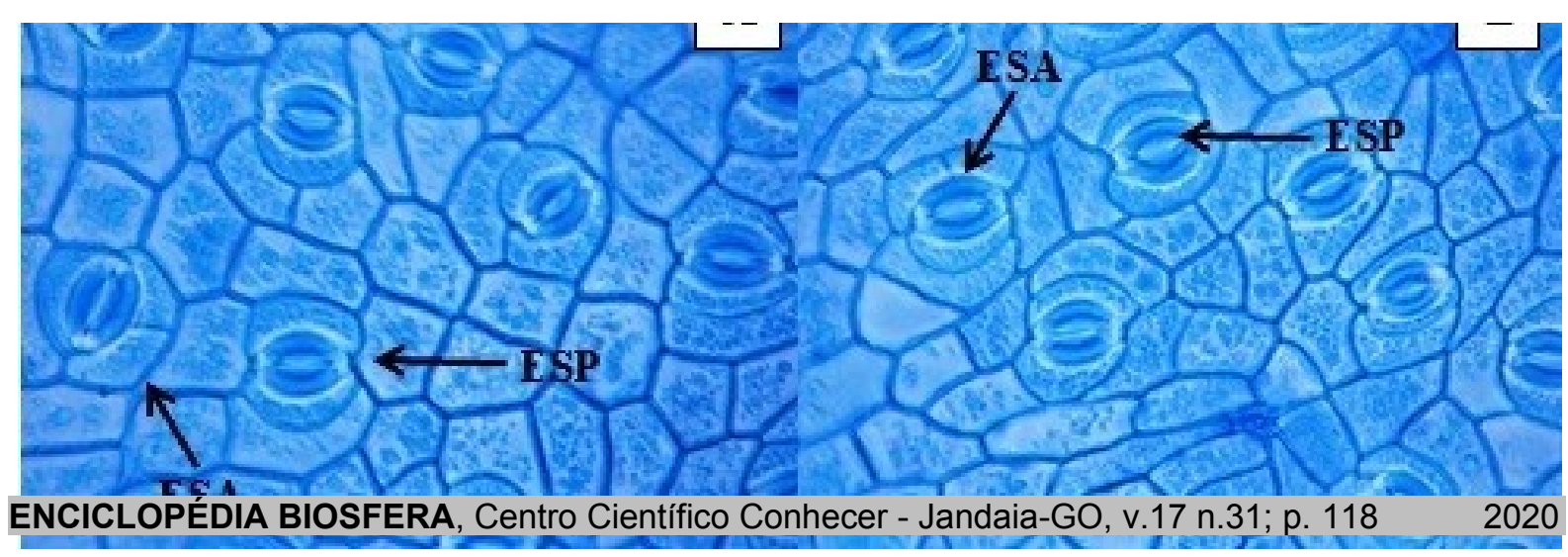

FIGURA 2 - Vista frontal (A e B) mostrando as células epidérmicas e os estômatos de Acacia mangium. ESP: estômatos paracíticos; ESA: estômatos anisocíticos. 
Folhas anfiestomáticas, caracterizado pela presença de estômato em ambas as faces da folha e frequentemente encontrado em planta de rápido crescimento, são comuns no gênero Acacia (METCALFE; CHALK, 1950). Essa característica surgiu como estratégia evolutiva e adaptativa de longo prazo, através da qual as plantas alteram as características anatômicas das folhas para lidar com mudanças permanentes nas condições ambientais (CAMARGO; MARENCO, 2011). Folhas anfiestomática possuem potencial para melhorar $\mathrm{o}$ suprimento de $\mathrm{CO}_{2}$ aos cloroplastos, fornecendo uma vantagem espécifica em folhas grossas, como a de Acacia mangium Willd, encurtando o caminho para o transporte de $\mathrm{CO}_{2}$ entre a atmosfera e os cloroplastos (DRAKE et al., 2018), além de aumentar a taxa fotossintética (MUIR, 2019). Por outro lado, apresença de estômatos em ambas as faces da folha exige investimentos adicionais de tecido de transporte de água das folhas para equilibrar a perda da água através da superficie adaxial, garantindo que os estômatos de ambas as superfícies sejam abastecidas com água (DRAKE et al., 2018), e ainda aumenta a exposição a potenciais agentes de doenças (MCKOWN et al. 2019).

Em secção transversal, a epiderme que reveste a folha é unisseriada, com parede periclinal externa cutinizada espessa em ambas as faces. A nervura central apresenta formato biconvexo, sendo composta por dois feixes vasculares na forma de arco (figura 3A). Nesta região se pode observar o floema completamente envolto por camadas de células esclerenquimáticas e ainda, logo abaixo da epiderme, ocorrem camadas de células colenquimáticas de formato angular (figura 3B).

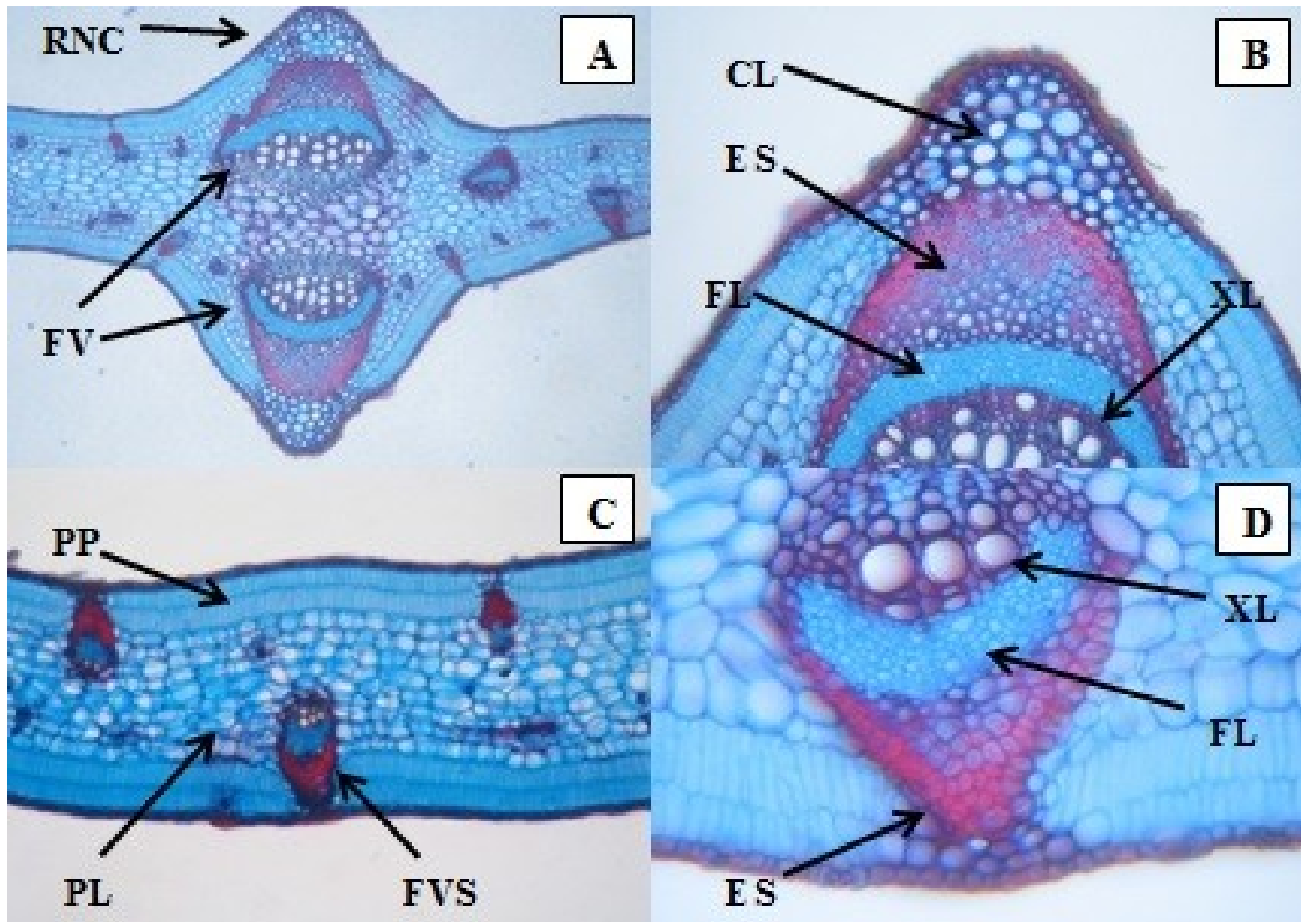

FIGURA 3 - Secções transversais da folha de A. mangium. A. Região da nervura central (RNC). FV: feixes vasculares. B. Detalhes dos tecidos externos aos feixes vasculares. CL: colênquima; ES: esclerênquima; FL: floema; $\mathbf{X L}$ : xilema. $\mathbf{C}$. Região do mesofilo. PP: parênquima paliçádico; PL: parênquima lacunoso; FVS: feixes vasculares secundários. D. Detalhe do feixe vascular secundário. 
A organização do mesofilo é isolateral com o parênquima paliçádico ocorrendo em ambas as faces da lâmina e o parênquima lacunoso no centro (figura 3C). O parênquima paliçádico é formado por duas camadas de células alongadas, dispostas paralelamente, podendo ser interrompido por projeções de fibras dos feixes secundários. O parênquima lacunoso é denso formado por um número maior de camadas de células, onde estão localizados pequenos feixes vasculares. Os feixes vasculares, entre a nervura central e o bordo são do tipo colateral, com floema externo ao xilema, sendo as nervuras envolvidas por células parenquimáticas e esclerenquimáticas (figura 3D).

A presença de cutina espessa em ambas as faces da folha possibilita 0 controle da transpiração (REYES et al., 2018). Segundo Combalicer et al. (2012) a espécie Acacia mangium Willd ao longo de seu desenvolvimento aumenta a espessura da cutina com a finalidade de reduzir a perda de água. A presença de epiderme unisseriada facilita a captação luminosa no interior da folha, sendo uma característica das espécies pertencentes à família Fabaceae (DUARTE; WOLF, 2005). Essa característica também foi encontrada em Acacia podalyriifolia A. Cunn ex G. Don (DUARTE; WOLF, 2005). A ocorrência de mesofilo isolateral, com parênquima paliçádico de duas a quatro camadas, como encontrado em Acacia mangium Willd, é considerada uma característica de espécies adaptadas as condições mais xéricas, de altas intensidades luminosas e temperatura (FAHMY, 1997). Essas características encontradas para Acacia mangium Willd podem justificar o fato da espécie se adaptar as condições de alta intensidade luminosa, quando plantada em área aberta, como mencionado por Tonini et al. (2018).

Densidade estomática de Acacia mangium Willd

A densidade estomática média para o plantio de nove meses, um ano e nove meses e de três anos e sete meses, foram respectivamente, 30,17 estômatos $/ \mathrm{mm}^{2}$, 29,74 estômatos $/ \mathrm{mm}^{2}$ e 33,08 estômatos $/ \mathrm{mm}^{2}$ (figura 4). A análise de variância (ANOVA), mostrou que há evidência moderada $(p=0,06)$ para afirmar que a densidade estomática difere em plantios de diferentes idades.

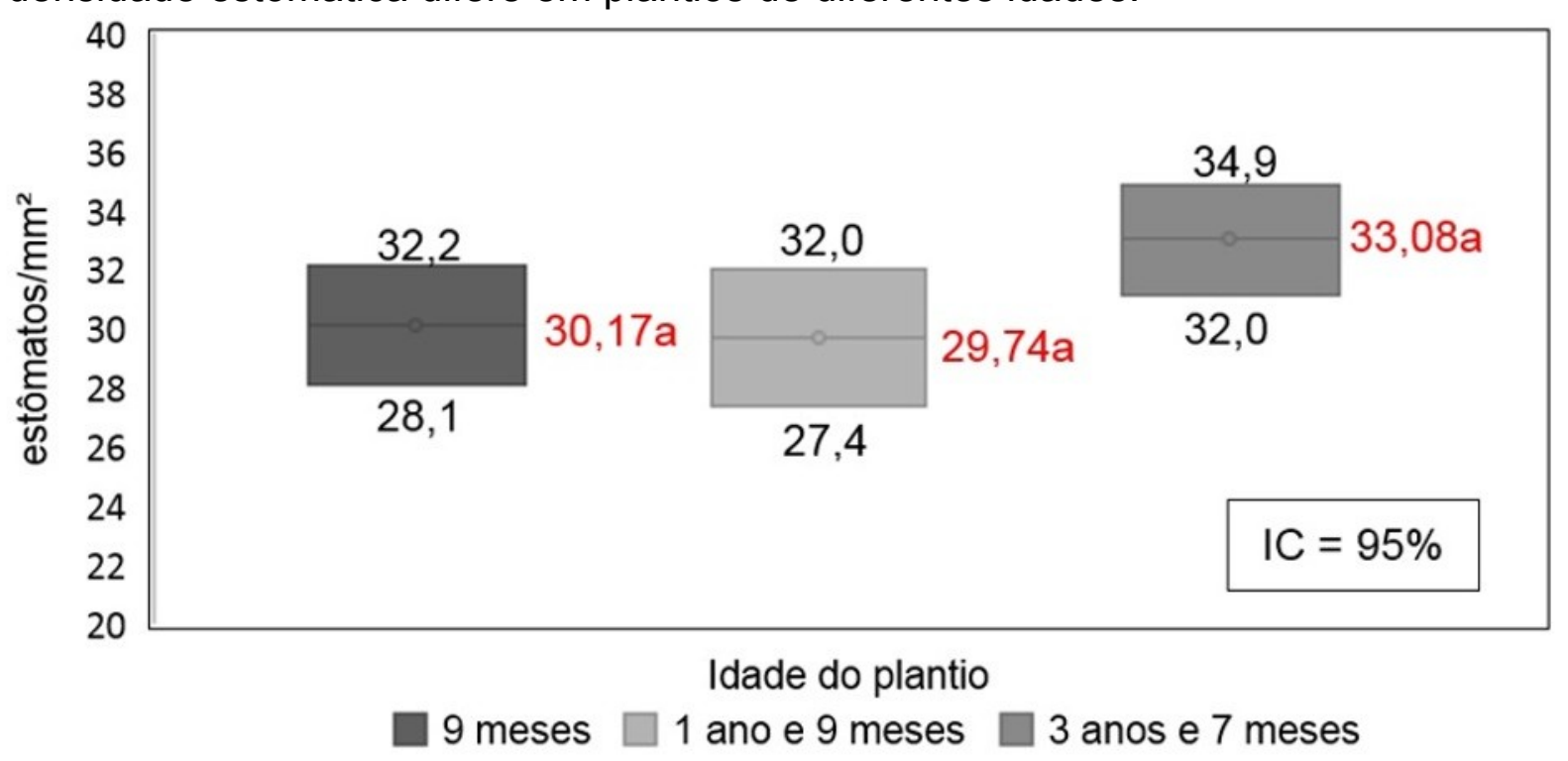

FIGURA 4 - Média de densidade estomática (em vermelho) para os indivíduos de diferentes idades com intervalo de confiança (IC) de 95\% de probabilidade (limite superior acima da barra e limite inferior embaixo da barra). As médias seguidas de letras iguais não diferem entre si, pelo teste Tukey, com $5 \%$ de probabilidade. 
Combalicer et al. (2012) avaliaram a densidade estomática de Acacia mangium Willd em plantios de dois e vinte anos de idade, no Sudoeste de Filipinas, e encontrou densidade estomática média de 27 estômatos por $\mathrm{mm}^{2}$ no plantio de 2 anos e 30 estômatos por $\mathrm{mm}^{2}$ no plantio de 20 anos. Os autores relatam que o aumento proporcional da densidade estomática com o aumento da idade, possibilita a espécie manter os níveis fotossintéticos ao longo do seu desenvolvimento.

Quanto a frequência de estômatos entre as duas faces da epiderme, não houve diferença na quantidade de estômatos presentes. A ocorrência de estômatos similar em ambas as faces das folhas permite maior condutância foliar ao $\mathrm{CO}_{2} \mathrm{e}$ consequentemente, maior taxa de fotossíntese (MCKOWN et al. 2019). Por outro lado, essa característica também ajuda a aumentar a transpiração apesar da presença da cutina espessa em ambas as faces (REYES et al., 2018).

\section{CONCLUSÕES}

As características anatômicas das folhas de Acacia mangium Willd justificam o seu potencial de rápido crescimento e adaptação em ambiente exposto a alta intensidade luminosa. As principais características que justificam a boa performance da espécie é a presença de epiderme unisseriada com parede periclinal externa cutinizada, mesófilo isolateral e estômatos em ambas as faces das folhas. Essas características, além de garantir o estabelecimento da espécie em plantios abertos, possibilita maior eficiência na captura da luz, e consequentemente, alta condutância ao $\mathrm{CO}_{2}$ e a fotossíntese, permitindo o seu rápido crescimento.

Neste estudo foi encontrada evidência moderada $(p=0,06)$ para afirmar que a densidade estomática difere entre os indivíduos de diferentes idades, indicando que a espécie mantém o mesmo ritmo de crescimento durante os anos avaliados.

\section{AGRADECIMENTOS}

A Universidade do Estado do Amazonas - UEA, pela oportunidade de realização deste trabalho de pesquisa, ao Grupo André Maggi por autorizar o acesso aos plantios da empresa para coleta de material botânico e ao técnico do LABAF/UFAM, Manoel Viana, pelo auxílio no preparo das lâminas.

\section{REFERÊNCIAS}

BONA, C. BOEGER, M. R.; SANTOS, G. O. Guia ilustrativo de anatomia vegetal. Curitiba: Ed. Holos, 2004

CAMARGO, M. A. B.; MARENCO, R. A. Density, size and distribution of stomata in 35 rainforest tree species in Central Amazonia. Acta Amazonica, v. 41, n. 2, p. 205212, 2011. Disponível em: <http: //dx.doi.org/10.1590/S0044-59672011000200004>. doi: 10.1590/S0044-59672011000200004

COMBALICER, M. S.; LEE, D. K.; WOO, S. Y.; HYUN, J. O.; PARK, Y. D.; et al.; Physiological Characteristics of Acacia auriculiformis A. Cunn. ex Benth., Acacia mangium Willd. and Pterocarpus indicus Willd. in the La Mesa Watershed and Mt. Makiling, Philippines. Philippines. JESAM, v. 1, n. 1, p. 14-28, 2012. Disponível em: $<$ https://www.researchgate.net/publication/279898641_Physiological_Characteristics _of_Acacia_auriculiformis_A_Cunn_ex_Benth_Acacia_mangium_Willd_and_Pteroca rpus_indicus_Willd_in_the_La_Mesa_Watershed_and_Mt_Makiling_Philippines> 
CUTLER, D.F.; BOTHA, T.; STEVENSON, D. W. Anatomia Vegetal: uma abordagem aplicada. Porto Alegre: Artmed, 2011

CUTTER E. Anatomia Vegetal Parte 1: células e tecidos. São Paulo: Roca, 2002. p. 143

DRAKE, P.L.; BOER, H. J.; SCHYMANSKI, S. J.; VENEKLAAS. Two sides to every leaf: water and $\mathrm{CO}_{2}$ transport in hypostomatous and amphistomatous leaves. New Phytologist, v. 222, n. 3. p. 1179-1187, 2018. Disponível em: <https://doi.org/10.1111/nph.15652>. doi: 10.1111/nph.15652

DUARTE, M. R.; WOLF, S. Anatomical characters of the phyllode and stem of Acacia podalyriifolia A. Cunn. ex G. Don (Fabaceae). Revista brasileira de Farmacognosia, v. 15, n. 1, p. 71-76, 2005. Disponível em: <http://dx.doi.org/10.1590/S0102-695X2005000100015>. doi: 10.1590/S0102695X2005000100015

FAHMY, G. M. Leaf anatomy and its relation to the ecophysiology of some nonsucculent desert plants from Egypt. Journal of Arid Environments, v. 36, n. 3, p. 499-525, 1997. Disponível em: <https://doi.org/10.1006/jare.1996.0217>. doi: 10.1006/jare.1996.0217

FERREIRA, C. S; CARMO, W. S; GRACIANO-RIBEIRO, D.; OLIVEIRA, J. M. F.; MELO, R. B.; FRANCO, A. C. Anatomia foliar de onze espécies lenhosas dominantes nas savanas de Roraima. Acta Amazonica, v. 45, n. 4, p. 337-346, 2015. Disponível em: <http://dx.doi.org/10.1590/1809-4392201500363>. doi: $10.1590 / 1809-4392201500363$

FERREIRA, L. M. M.; TONINI, H. Comportamento da castanha-do-brasil (Bertholletia excelsa) e da cupiúba (Goupia glabra) em sistema agrosilvicultural na região da Confiança, Cantá-Roraima. Acta Amazonica, v. 39, n. 4, p. 835-842, 2009. Disponível em: < http://dx.doi.org/10.1590/S0044-59672009000400012>. doi: 10.1590/S0044-59672009000400012

JUSOH, I.; SUTEH, J. K.; ADAM, N. S. Growth and Yeld of Acacia mangium based on permanent sampling plots in plantation. Transactions on Science and Technology, v. 4, n. 4, p. 513-518, 2017. Disponível em: <http://tost.unise.org/pdfs/vol4/no4/4x4x513×518.pdf>

LEME, F.M.; DIAS, E. S. Ecological interpretation of the leaf anatomy of amphybious species of Aeschynomene L. (Leguminisae-Papilionoideae). Brazilian Journal of Biology, v. 74, n. 1, p. 41-51, 2014. Disponível em: < http://dx.doi.org/10.1590/15196984.16212>. doi: 10.1590/1519-6984.16212

MACHADO, M. R.; CAMARA, R.; SAMPAIO, P. T. B.; FERRAZ, J. B. S.; PEREIRA, M. G. Silvicultural performance of five forest species in the central Brazilian Amazon. Acta Amazonica, v. 48, n. 1, p. 10-17, 2018. Disponível em: <http: //dx.doi.org/10.1590/1809-4392201700602>. doi: 10.1590/1809-4392201700602 
MCKOWN, A. D.; KLÁPŠTĚ, J.; GUY, R. D.; COREA, ORA.; FRITSCHE, S.; EHLTING, J.; EL-KASSABY, Y. A.; MANSFIELD, S. D. A role for speechless in the integration od leaf stomatal patterning with the growth vs disease trade-off in poplar. New Phytolologist, v. 223, n. 4, p. 1888-1903, 2019. Disponível em: <https://doi.org/ 10.1111/nph.15911>. doi: 10.1111/nph.15911.

METCALFE, C. R.; CHALK, L. Anatomy of the dicotyledons: Leaves, stem, and wood in relation to taxonomy with notes on economic uses. Oxford: At The Clarendon Press, 1950. p. 479

MUIR, C. D. Is amphistomy an adaptation to high light? Optimality models of stomatal traits along light gradients. Integrative and Comparative Biology, v. 59, n. 3, p. 571-584, 2019. Disponível em: <https://doi.org/10.1093/icb/icz085>. doi: 10.1093/icb/icz085

REYES, M. G.; CARMONA, G. S. L.; FERNÁNDEZ, M. E. Aspectos fisiológicos y de aprovechamiento de Acacia mangium Willd. Uma revisión. Revista colombiana de ciências Hortícolas, v.12, n. 1, p. 244-253, 2018. Disponível em: <https://doi.org/10.17584/rcch.2018v12i1.7340>. doi: 10.17584/rcch.2018v12i1.7340

RODRIGUES, J. K.; MENDONÇA, M. S.; GENTIL, D. F. O. Aspectos biométricos, morfoanatômicos e histoquímicos do pirênio de Bactris marajá (Arecaceae). Rodreguésia, v. 66 , n. 1, p. 75-85, 2015. Disponível em: < http://dx.doi.org/10.1590/2175-7860201566105>. doi: 10.1590/2175-7860201566105

SCHÖNGART, J.; GRIBEL, R.; FONSECA-JUNIOR, S. F.; HAUGAASEN, T. Age and Growth Patterns of Brazil Nut Trees (Bertholletia excelsa Bonpl.) in Amazonia, Brazil. BIOTROPICA, v. 47, n. 5, p. 550-558, 2015. Disponível em: <https://doi.org/10.1111/ btp.12243>. doi: 10.1111/btp.12243

SILVA, B. R. S.; GIL, A. S. B.; SIMÕES, A. O. Anatomia de órgão vegetativo como subsídio à taxonomia de Geissospermum (Apocynaceae-Rauvolfioideae). Rodriguésia, v. 69, n. 4, p. 2093-2107, 2018. Disponível em: < http://dx.doi.org/10.1590/2175-7860201869439>. doi: 10.1590/2175-7860201869439

SOUZA, C. S. C. R.; SANTOS, V. A. H. F.; FERREIRA, M. J.; GONCALVES, J. F. C. Biomass, growth and ecophysiological responses of young plants of Bertholletia Excelsa Bonpl. Subjected to different levels of irradiance. Ciência Florestal, v. 27, n. 2, p. 557-569, 2017. Disponível em: <http://dx.doi.org/10.5902/1980509827736>. doi: $10.5902 / 1980509827736$

TONINI, H. SCHWENGBER, D. R.; MORALES, M.M.; MAGALHÃES, C. A. S.; OLIVEIRA, J. M.F. Growth, biomass, and energy quality of Acacia mangium timber grown at diferente spacings. Pesquisa agropecuária brasileira, v. 53, n. 7, p. 791799, 2018. Disponível em: < http://dx.doi.org/10.1590/s0100-204x2018000700002>. doi: 10.1590/s0100-204x2018000700002

VAZ, P. P.; ALVES, F. M.; ARRUDA, R. C. O. Systematic implications of leaf anatomy in the Neotropical Mezilaurus clade (Lauraceae). Botanical Journal of the 
Linennean Society, v. 189, n. 2, p. 186-200, 2019. Disponível em: < https://doi.org/10.1093/botlinnean/boy078>. doi: 10.1093/botlinnean/boy078

ZHOU, Q. Z.; JIANG, Z.; ZHANG, X.; ZHANG, T.; ZHU, B. C.; LI, Y.; ZHAO, F.; ZHAO, Z. Leaf anatomy and ulytastructure in senescing ancient tree, Platycladus orientalis L. (Cupresssaceae). PeerJ, v. 7, p. 1-22, 2019. Disponível em: https://peerj.com/articles/6766/. doi: 10.7717/peerj.6766 